\title{
The Complementary Relationships between Reading and Writing in Children with and without Writing Difficulties
}

\author{
Åsa Wengelin and Barbara Arfé
}

\section{Introduction}

This chapter deals with the relations between the processes of reading and writing, and thus the relation between reading and writing difficulties. Whereas the onset of spoken language development is assumed to happen "naturally" and with little effort for most children, the onset of written language acquisition generally happens later, and for many children not until they have received instruction in school. Children in different countries start school at different ages and acquire orthographies of different complexities concerning phonology, orthography, morphology and syllable structure. Therefore, different language systems will pose different challenges to writers and readers at different stages of the developmental process (Arfé, Dockrell, \& Berninger, 2014). For example, in shallow orthographies spelling and decoding will be mastered earlier than in deep orthographies (e.g., Babayigit \& Stainthorp, 2011), and this might to some extent affect the development of higher level processes, such as meaning-making processes in reading and writing.

What seems to be relatively universal in languages with alphabetic orthographies is however, that whereas some children learn to read and write before they start school and some even appear to crack the code more or less overnight, many do not and therefore require more explicit instruction. The period before starting to read and write is generally known as the emergent-literacy period, during which the activities of reading and writing cannot always be disentangled from each other. Research on emergent literacy is a vast research field on its own that can likely offer explanations for some of the phenomena discussed in this chapter. While keeping this in mind, we have chosen to delimit our chapter to research dealing with the activities often described as "conventional" reading and writing, as defined by McGee \& Richgels (1996):

Conventional readers and writers read and write in ways that most people in our literate society recognize as 'really' reading and writing. For

(C) KONINKLIJKE BRILL NV, LEIDEN, 2018 | DOI: 10.1163/9789004346369_004

This is an open access chapter distributed under the terms of the prevailing CC-BY-NC License at the time of publication. 
example, they use a variety of reading strategies, know hundreds of sight words, read texts written in a variety of structures, are aware of audience, monitor their own performances as writers and readers, and spell conventionally.

$$
\text { p. } 3^{\circ}
$$

This chapter focuses on such conventional processes at word and text level. We present two different, but complementary, perspectives that exist in research: One that considers reading and writing as two separate-though relatedprocesses (e.g., Berninger, Abbott, Abbott, Graham, \& Richards, 2002; Juel, 1988; Mehta, Foorman, Branum-Martin, \& Taylor, 2005) and examines the concurrent and longitudinal relationships between these two literacy skills, and one that considers reading as a component of the writing process, and examines the contribution of reading-during-writing processes to children's and adults' writing (e.g., Alamargot, Chesnet, Dansac, \& Ros, 2006; Wengelin, Leijten, \& Van Waes, 2010). We will discuss both perspectives with reference to reading and writing difficulties.

\section{Reading and Writing as Separate Processes}

In cognitive research, reading and writing have often been considered two separate objects of inquiry, characteristic of two distinct research areas: reading research and writing research (Connelly, 2014). The connections between these two areas have long been limited and sporadic. This division has led to the development of separate models accounting either for reading (see Gough \& Tunmer, 1986; Kintsch, 2004) or writing (Berninger, Vaughan et al., 2002; Hayes \& Flower, 1980), and attempts to integrate reading and writing processes-and thus reading and writing difficulties - in a unitary cognitive model have been very few to date (Kintsch \& van Dijk, 1978). In the next two parts, we will take a closer look at models that explain reading and writing difficulties at word level and at text level.

\section{Models That Explain Reading and Writing Difficulties at Word Level}

The relationship between word reading and spelling is one of the most debated issues in reading and spelling research (Tainturier \& Rapp, 2002). One view is that they are two distinct processes, with different components, with the only exception being an a-modal semantic system (Caramazza, 1988). Another view is that reading and spelling depend on shared processing components, with the exception of their peripheral processes. The models that have been clas- 


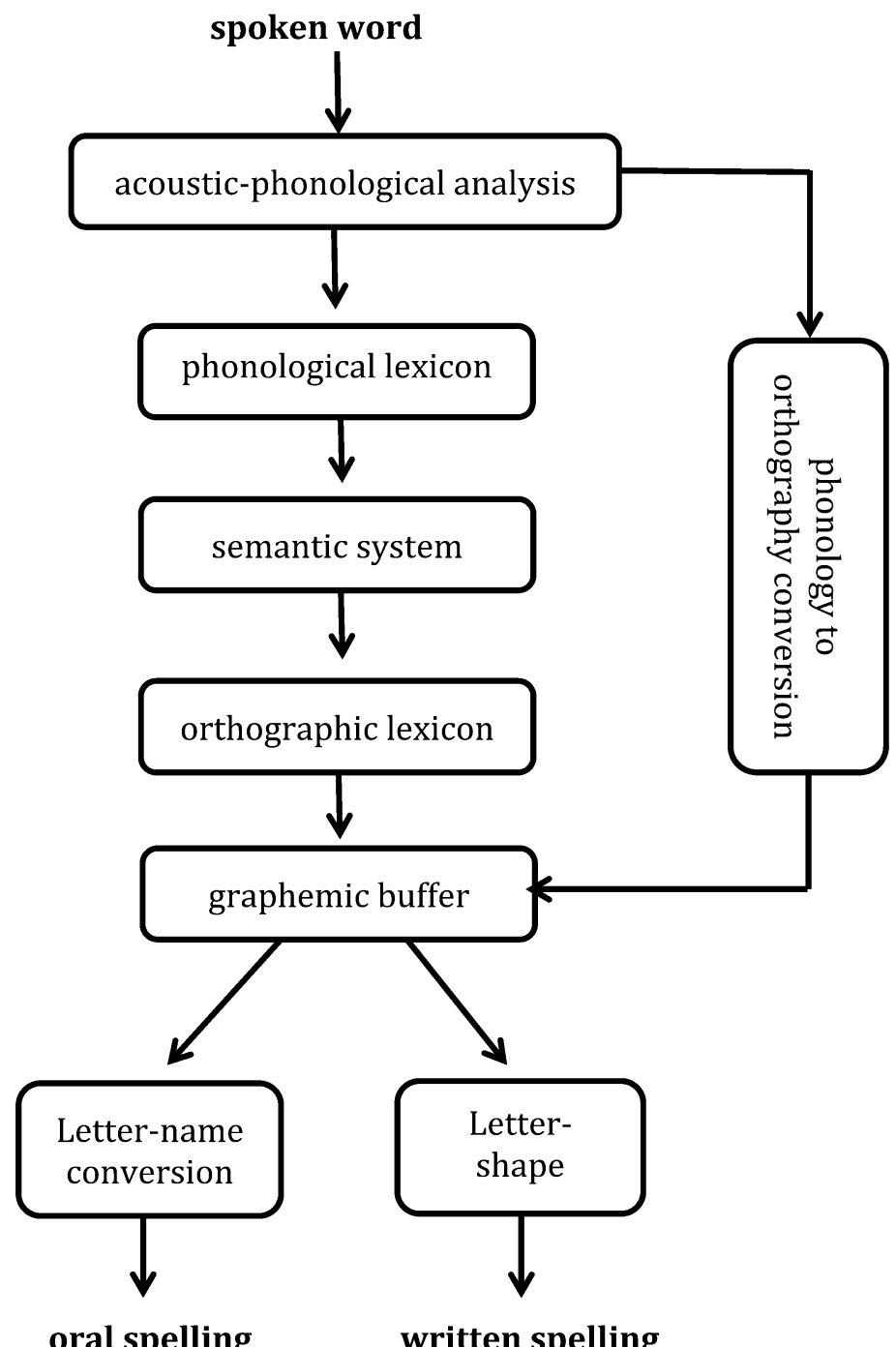

FIGURE 3.1 A dual route spelling model

BASED ON TAINTURIER \& RAPP (2002)

sically used to describe the functional architecture of the reading and writing process at the word level—dual route models (e.g., Coltheart, 1978; Coltheart, Curtis, Atkins, Haller, 1993; Tainturier \& Rapp, 2002)—view written spelling and reading as involving distinct processing components or modules, which are assumed to be selectively impaired in adults or children. However, they also describe components that are common to the two processes, albeit an explicit focus on these common modules is infrequent (see Figures 3.1 and Figure 3.2). 


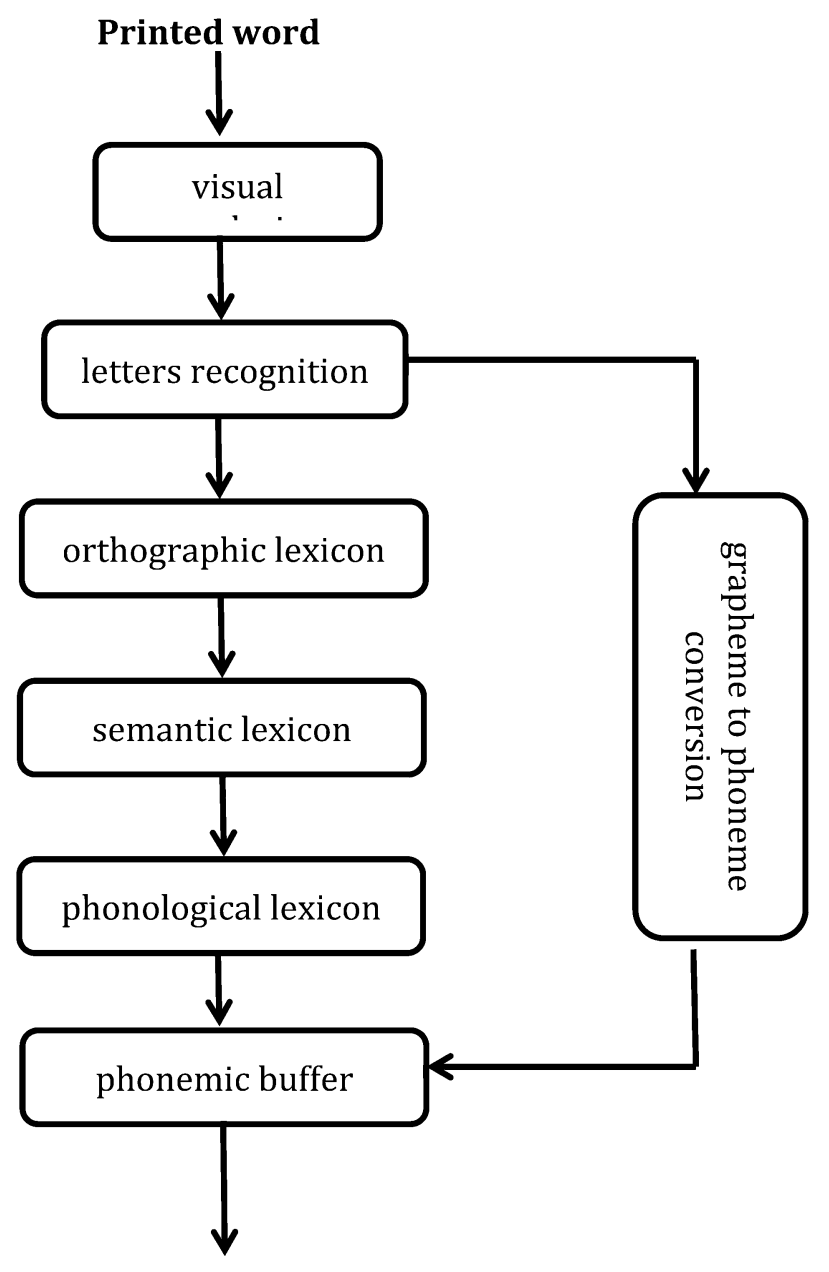

spoken word

FIGURE 3.2 A dual route reading model

BASED ON WANG ET AL. (2014)

The classical dual route models (e.g., Coltheart, 1978; Tainturier \& Rapp, 2002) describe reading and writing as processes consisting of sequential processing of visual/phonological, semantic, and orthographic information, supported by two different peripheral systems for the analysis of the input (auditory vs. visual). Both of these can temporarily store word representations to be produced by different output systems. Furthermore, both assume that word reading and word spelling can occur through two alternative processes or "routes": the lexical, where a word is read by retrieving it from a mental lexicon containing knowledge about the spelling and pronunciation of the letter 
strings, and the sublexical, in which readers do not use their mental lexicon to read words, but make use of conversion rules relating segments of orthography to segments of phonology. Today, the independence of these two routes is debated (see Coltheart, 2005; Coltheart et al., 1993). However, in this chapter we focus more on the components described by this model than on the assumption of two independent routes for reading or spelling. In their more recent versions, dual route models (DRC: dual route cascaded) do not assume sequential processing mechanisms, but cascade mechanisms, that is, a system of spreading activation among different units of representations (e.g., words, letters; Coltheart et al., 1993; Coltheart, 2005). Nevertheless, the components are similar to those of the original models. According to both of the earlier-mentioned views on the relation between reading and spelling, some components of the dual route models are specific to only the reading or written spelling processes. Specific to the spelling system are the acoustic-to-phonological conversion component, that converts the auditory input into phonological representation; the phonology-to-orthography conversion system (POC) for conversion of the phonological units into orthographic units; and the graphemic buffer, a storage system where these units are assembled into sequences of abstract letters or letter strings (Figure 3.1). However, specific to reading are the components of visual analysis and letter recognition, and the grapheme-to-phoneme conversion system, based, as in the spelling process, on sublexical routines (Figure 3.2).

More debate exists around the status of the lexical representations involved in the reading and spelling processes. With the exception of the semantic system (a repository of word meanings), which, according to both views, is shared by oral language, reading, and spelling, the shared-components and distinctcomponents views make different hypotheses about the lexical representations involved in reading and spelling. The shared-components hypothesis assumes, for example, the existence of a single orthographic lexicon (a store of orthographic word forms) shared by the reading and spelling process, although the access procedures to it are considered to be process specific. By contrast, the distinct-components hypothesis distinguishes between an orthographic lexicon in input, which is necessary to recognize written words in reading (Figure 3.2), and an orthographic lexicon in output, used to produce written words by spelling (Tainturier \& Rapp, 2002). The same could be assumed for the phonological lexicon (see Figures 3.1 and 3.2).

Connectionist models (e.g., Seidenberg \& McClelland, 1989) and the more recent triple word form theory (Richards et al., 2006) emphasize the role of the interrelationships between the different word representations (phonological, orthographic, semantic, and morphological) in reading and spelling. Over- 
coming the traditional separation between lexical and sublexical procedures and between components of reading and spelling in dual route models, connectionist models suggest that learning to read and write requires mapping orthographic representations of words onto phonological, morphological (and semantic) representations, which are the product of oral language development (similar to what is stated by the amalgamation theory of Ehri, 2005). The triple word form theory assumes, for example, that the quality of writtenword spelling and reading may depend to a large degree on the child's ability to compute the interrelationships among the segments of phonological, morphological, and orthographic word forms. Hence, it is this amalgamation or crossmapping of word representations that underpins reading and spelling. This view has recently received substantial support from behavioural and neuroimaging studies conducted with individuals with dyslexia (e.g., Richards et al., 2006), and longitudinal studies conducted with typically developing children (e.g., Nunes, Bryant, \& Bindman, 1997), for both reading and spelling.

\section{Models That Explain Reading and Writing Difficulties at Text Level}

At text level, probably the most widely used model to explain reading problems is the simple view of reading (e.g., Hoover \& Gough, 199o). It depicts reading as consisting of two separate components: decoding (D) and linguistic comprehension $(\mathrm{L})$, both necessary for reading texts and neither of them sufficient by itself. Reading comprehension $(\mathrm{R})$ is seen as a product of these two components. Thus, the model is synthesized by the following formula: $\mathrm{R}=\mathrm{D} X \mathrm{~L}$. Progress in reading requires that both components be non-zero. However, assuming that the two components can independently contribute to reading, the model hypothesizes that poor reading comprehension skills can follow from one of these three conditions: (a) when decoding skills are adequate but linguistic comprehension is weak (poor comprehenders who are good decoders), (b) when linguistic comprehension is adequate but decoding skills are not (poor decoders who are good comprehenders), and (c) when both skills are compromised (poor decoders who are also poor comprehenders [Hoover \& Gough, 1990]). This hypothesis is supported by empirical data (Juel, 1998).

Although the model assumes that the two components are equally important for the success of reading, decoding is hypothesized to contribute to reading comprehension more than linguistic comprehension until children acquire sufficient decoding skills to read fluently, then linguistic comprehension becomes more important (Hoover \& Gough, 1990).

There has been an explicit attempt to extend the simple view of reading model to writing (Juel, 1988), although the reading and writing processes at 
text level are assumed to rely on different components. Like the simple view of reading, the simple view of writing assumes that writing is the product of two components: transcription (or the ability to convert linguistic representations in written symbols) and text generation skills (i.e., the ability to generate ideas linguistically). As in reading, the two key components in writing can be impaired individually or in combination; that is, poor text generation skills are assumed to result either from a) selective problems with transcription (i.e., spelling and handwriting) in poor spellers with good text generation skills, b) selective text generation difficulties, in poor writers who have adequate transcription skills, or c) a combination of the two problems, in poor spellers who also are poor writers (see Juel, 1998). Studies on subtypes of writing problems seem to support this model (Wakely, Hooper, de Kruif, \& Swartz, 20o6). In addition, also similar to reading, writing transcription skills are assumed to contribute most to text production during the first years of school, and text generation is hypothesized to contribute more, once transcription has been automatized (Berninger, Vaughan et al., 2002). Indeed, spelling and handwriting problems seem to constrain text generation, requiring significant cognitive resources the writer needs to address higher level writing processes, such as idea generation and translation. Therefore, writers who are poor in transcription tend to be poor in text production too. However, unlike what emerged from reading, some research data suggest that in writing poor transcription skills do not always involve poor text production (e.g., Connelly, 2014), and that in highly regular orthographies, from early grades transcription contributes less to text production than do text generation skills (Babayigit \& Stainthorp, 2011).

Despite the attempt to use the same types of models to explain reading and writing, models of reading and writing at the word and text levels have not yet been used to explain how these two processes can be interrelated.

\section{Closing the Gap?}

There is a long tradition not only of separation between the studies of reading and writing but also between the ways they are taught (Fitzgerald \& Shanahan, 2000). A possible explanation for this could be that for a long time full participation in democratic societies required good reading skills but only limited writing skills. Over the past decade, however, with the rapid increase in the use of the internet, social media, and various portable communication devices, writing has become an everyday activity for most people around the globe. Brandt (2011) has even described this movement away from reading as 
the main literacy activity, as a move from mass reading to an era of mass writing. Thus, both writing and reading processes are integrated in several everyday school activities, such as note taking and summary writing (Hebert, Gillespie, \& Graham, 2013), or writing syntheses from sources (Boscolo, Arfé, \& Quarisa, 2007), but they also play important roles in leisure activities such as the use of social media, narrative games, and blogging. Examining activities that combine reading and writing is important in understanding how children with reading and writing difficulties use writing functionally, i.e., to learn. In addition, despite the use of distinct clinical labels for reading and writing problems (e.g., dyslexia, dysgraphia, reading comprehension problems, problems of written expression), in reality, difficulties in learning reading and writing are often associated in the scholastic population: A number of children with dyslexia (i.e., word-level reading problems) experience writing problems at the word level (e.g., Angelelli, Marinelli, \& Zoccolotti, 2010) and at the text level (e.g., Sumner, Connelly, \& Barnett, 2014). Moreover, another group of children who consistently experience reading problems at the text level-poor comprehendersappear to show similar problems in writing (e.g., Juel, 1988).

In the attempt to explain the association between reading and writing difficulties, cognitive and education researchers have elaborated three hypotheses. One is that in these children the same cognitive or language deficits might underpin the processing of written language in both reading and writing (Angelelli et al., 2010; Carretti, Re, \& Arfé, 2013). A second hypothesis is that poor reading skills affect writing, because writing involves reading, whose mechanisms are impaired (Johansson, Johansson, Wengelin, \& Holmqvist, 2008; Wengelin, Johansson, \& Johansson, 2014). The third and last hypothesis is that reading and writing processes are related developmentally, and hence poor readers tend to become poor writers (see Juel, 1988) or, conversely, poor writing skills affect the development of higher order reading skills (see Berninger, Abbott, et al., 2002). These three hypotheses are not mutually exclusive. It is plausible to assume that the same underlying cognitive and/or language deficits hinder the development of both reading and writing (we will discuss how in the next paragraphs) and that thus these two processes are developmentally interconnected.

\section{Separate, Though-Related, Processes}

As the models of reading and writing presented in part 2 show, reading and writing processes appear to rely on different functional mechanisms. For example, from the lowest levels of elaboration, written words are first accessed 
through the child's visual system in reading, through the hearing system, in dictation, or through the semantic system (i.e., long term memory) in written naming or written composition. Therefore, reading and writing could in principle pose different kinds of challenges to poor writers/readers in these initial stages of word elaboration (Tainturier \& Rapp, 2002). In addition, reading is comprehension while writing is mainly production. That is, in reading the meaning-making process requires the child to follow text signals to reconstruct the meaning of a text, but writing requires the child himself or herself to generate meaning, its organization, and signals for the reader to connect information in the produced text, similar to oral language production. It is thus not surprising that the prevalence of writing problems greatly exceeds that of reading problems in the scholastic population (see Katusic, Colligan, Weaver, \& Barbaresi, 2010). However, in many cases writing and reading problems are associated. In their population-based study, Katusic and colleagues found that cumulative incidence rates of writing disorders varied from about 7 to $15 \%$. However, among all the written-language disorders they could identify, only $25 \%$ were not associated with a reading disability.

Hence, despite their differences, reading and writing cannot be studied in isolation if the aim is to explain how these processes work in the child's mind (Berninger, Abbott et al., 2002). They are two complex language phenomena that rely on a complex set of relationships between oral and written language, among visual, auditory, and phonological skills, and between receptive and expressive language mechanisms. Word recognition and written spelling processes are based on the use of the same word representations: orthographic, phonological, and morphological (and semantic). Problems in constructing or storing some of these word representations in memory would likely affect both reading and writing (Angelelli et al., 2010). On the other hand, developing these representations in one of the two can support their use in the other. Berninger, Abbott et al. (2002) found that word reading skills explained spelling and handwriting in typically developing children, but the reverse is also true. As spelling new words requires the writer to attend to the orthographic details (i.e., letter order) of words, and to sub-lexical sound-letter relationships in a comprehensive manner, spelling also influences reading by fostering the development of orthographic representations (Ouellette \& Sénéchal, 2008). Evidence of such influence comes from longitudinal studies, showing that early writing during preschool has a predictive influence on first graders' reading (e.g., Shatil, Share, \& Levin, 2000), and from experimental training studies on more and less shallow orthographies (e.g., Shahar-Yames \& Share, 2008). Spelling, like decoding words, may act as a self-teaching mechanism (Shahar-Yames \& Share, 2008): Each time the child attends to the orthographic details of a new word, recod- 
ing the printed word to sound or the reverse, this specifies and consolidates its representation in memory.

As regards the production and comprehension of texts, these processes, though clearly different, involve similar communicative skills and linguistic resources. For example, knowledge of vocabulary, grammar, and discourse can be considered factors underlying both reading and writing (Babayigit \& Stainthorp, 2011; Olinghouse, 2008). Also, the ability to relate pieces of information and represent their connections in a mental model is critical in both comprehending and producing a written text (Arfé \& Boscolo, 2006). Finally, reading and writing involve similar cognitive skills, such as working memory (Cain, Oakhill, \& Bryant, 2004; Swanson \& Berninger, 1996), metaknowledge (Carretti et al., 2013), and monitoring abilities (Hayes \& Berninger, 2014; Vorstius, Radach, Mayer, \& Lonigan, 2013). Difficulties at one or more of these levels can likely affect both the reading and writing processes.

The relation between these higher-order processes has mainly been addressed in four different ways: (a) correlational studies of children's reading and writing skills, (b) studies that examine patterns of relations that exist between different aspects of reading and writing knowledge on the one hand and external variables on the other, (c) interventions of one of the two in order to improve the other (Fitzgerald \& Shanahan 200o), and (d) longitudinal studies (e.g., Juel, 1989; Cain et al., 2004) which examine the developmental relationship between the acquisition of reading and writing skills respectively.

Due to space limitations, we do not focus on those but instead concentrate on two studies that explored the complex relationships between reading and writing processes by means of advanced statistical analyses. An important aspect of both these studies is that not only do they focus on the relation between reading and writing, but also on the relation between these literacy skills and other linguistic skills. The rationale behind this is to disentangle effects generated by linguistic modality (oral vs. written) from those of linguistic process (perception vs. expression). Figure 3.3 shows how the four linguistic functions, listening, speaking, reading, and writing, can be categorised across these two dimensions. It could for example be the case that reading and writing share more traits with their respective correspondents in the oral modality than with each other.

The first of the two studies in focus was carried out by Mehta et al. (2005) and investigated whether literacy could be described as a unitary construct, if so whether this construct could be distinguished from a more general language competence, i.e., whether written language skills are separable from a more general verbal ability, and finally the relative roles of teaching on the one hand and students' prior knowledge on the other in predicting literacy outcomes. 
Linguistic modality

\begin{tabular}{|c|c|c|c|}
\hline \multirow{2}{*}{$\begin{array}{l}\text { Linguistic } \\
\text { process }\end{array}$} & & Oral & Written \\
\hline & Reception & Listening & Reading \\
\hline & Expression & Speaking & Writing \\
\hline
\end{tabular}

FIGURE 3.3 The four language functions distributed across the dimensions of linguistic modality and linguistic process

They found that competencies in word reading, passage comprehension, and spelling could be adequately explained by a common factor that they named "literacy factor", which at the individual level was distinct from a more general language competence. Interestingly, text writing was less related to this factor. Their interpretation of this was that writing is influenced by more factors than word reading, spelling, and passage comprehension, and is therefore a more complex process. The latter was supported by a slightly disappointing result generated from classroom data that of five literacy outcomes measured in the study, the only one to be impacted by teaching quality was writing.

The second study in question was carried out by Berninger and Abbott (2010) and focused on the relations between higher-level processes in comprehension and expression of ideas in spoken and written language. They aimed at investigating whether the four skills of speaking, listening, reading, and writing are separate but interacting systems, or whether they draw on a single underlying system, independent of end organ (ears, eyes, mouth, and hand) and modality (oral vs. written language). A factor analysis of data generated by children in grade 1-7 revealed that a four-factor model of language by ear, mouth, eye, and hand fit their data better than a one-factor model for a single language system. Berninger and Abbott concluded that the functional systems that develop as children perceive language through their ears or eyes and express ideas in language through their mouth or hand may be separable and have distinct characteristics because "their unique histories in interacting with the world in contrasting ways create different paths to the higher order language skills in the mind" (p. 13).

This interpretation is further supported by additional data collected by the same authors, profiling children's language skills. These data showed that whereas most children's strengths and weaknesses in speaking, listening, read- 
ing and writing changed over time, a small group appeared to retain stable dissociations between the four skills. Most frequent was stable weaknesses in writing, compared to the other three skills. This would not have been possible with a unitary language system.

Having drawn the conclusion that the four systems are separate, Berninger and Abbott (2010) set out to investigate whether and to what extent they are interrelated. Using regression analysis, they analysed to what extent skills related to three of the languages systems contributed uniquely to the fourth assuming that such unique contributions would indicate that they were separate but interrelated. Such relations could be expected to occur across any of the two dimensions, modality and linguistic process, i.e., horizontally or vertically in the table in figure 3.3.

Starting out with receptive processes, in both modalities, i.e., listening comprehension and reading comprehension, they found that both contributed unique variance to each other. This indicates that their measures of oral and written language comprehension do not assess a common core of receptive functions. These results were more or less consistent across school grade. Turning to expressive processes in both modalities, i.e., speaking and writing, they found similar-if not as consistent as across grade—-results for oral and written expression. Their main conclusion of these results is that language functions in the two modalities - especially the receptive processes—do not share a common core.

As regards the relations between linguistic processes within each modality, they found that while reading comprehension and writing contributed unique variance to each other, speaking and listening comprehension did not. Viewed in isolation these results could indicate that while spoken language functions draw on a similar language core, their written correspondent does not. However, as the earlier mentioned profiling showed that oral skills were not completely identical, Berninger and Abbott rather concluded that they draw on a common language core to a greater extent than their correspondent written functions.

To sum up the results by Mehta et al. (2005) and Berninger and Abbott (2010), these authors suggest that we have separate language systems for the four functions speaking, listening, reading, and writing. Furthermore, to the extent that they are interrelated, these interrelationships seem to be modality dependent and stronger for the spoken modality than for the written. Writing is the most complex system and therefore most vulnerable to language disorders and developmental delays. These results support and explain studies on reading and writing difficulties which have shown that if and when oral language problems (Nauclér \& Magnusson, 2002) or reading difficulties 
(Hatcher, Snowling and Griffiths, 2002) are overcome, written production frequently continues to suffer.

\section{The Reading Component in the Writing Process}

So far we have dealt with relations between the reception of texts written by others on the one hand and the writer's own production of texts on the other. However, most models of writing assume that text production implies some amount of reading (see Hayes \& Berninger, 2014; Torrance \& Wengelin, 2010; Wengelin, et al., 2010). For example, revision typically involves reading the target sentences or text the writer has written (Hayes, Flower, Schriver, Stratman, \& Carey, 1987; Kaufer, Hayes, \& Flower, 1986). Hence, a reading component is considered in recent accounts of the writing process (Hayes \& Berninger, 2014).

Hayes (1996) suggested that reading contributes to writing tasks in three distinct ways: reading for understanding, reading to define the writing task, and reading to evaluate. Reading for understanding and reading to define the task are, however, only considered when external sources are used (e.g., to provide the reader with content and a reason to write the text). Reading to evaluate, on the other hand, is considered when the writer is reading his/her own emerging text, for example in order to revise the text. This could take place either during the actual writing process, when the writer looks at his or her emerging text, or as a proof reading process after a first draft has been completed. Hayes (1996) argues that when reading to revise, people read not only to represent the text's meaning but to identify text problems like bad diction, wordiness, and poor organization.

Interestingly, errors may not be corrected immediately when they are detected, indicating that the interplay between reading and writing during text production is an intricate process in need of more research. For example, Van Waes, Leijten, and Quinlan (2010) showed that writers frequently detected errors in a sentence they were composing, but completed the partial sentence first and then corrected the error.

In addition to reading for revision, Hayes (1996) recognized that reading for evaluation may also be performed to facilitate other parts of the writing process (e.g., if communicative and rhetorical goals are achieved in the text, if the text conforms to a given text genre, and to spot general text improvements). Similarly, Holmqvist, Holsanova, Johansson, and Strömqvist (2004) have argued that writers frequently look back to refresh their memory, and Wengelin and colleagues (Wengelin et al., 2009) proposed that writers look at their emerg- 
ing text to prompt content generation, to maintain cohesion, and to engage in meta-cognitive strategies.

Recently, questions have been raised about (a) the extent to which readingor any type of feedback from the emerging text - is really necessary for text production (Torrance, Rønneberg, Johansson, \& Uppstad, 2016) as suggested by others (e.g., Alamargot et al., 2006; Nottbusch, 2010; Torrance \& Wengelin, 2010; Wengelin, et al., 2009) and (b) how reading during writing differs from reading a static text produced by someone else (Torrance, Johansson, Johansson, \& Wengelin, 2016). Most likely, it depends on the writing task, but results from a study of blind writing (each character was represented on the screen by an $\mathrm{x}$; Torrance et al., 2016) suggest that for shorter texts ( $\approx 300$ words in the study by Torrance et al.) visual feedback may not be as necessary as previously thought for the production of a coherent text. Writers left more uncorrected errors in the texts produced in the blind condition than in the control condition, but no other differences were noted between the written products produced in the different conditions. These results are to a certain extent supported by Johansson and colleagues (Johansson, et al., 2008; Johansson, et al., 2010) who showed that writers read their texts surprisingly little and that there was no correlation between text characteristics such as lexical diversity or text length, and how much a writer reads the text produced to that point during the writing process. For longer texts, however, it appears very unlikely that access to the emerging text would not play a role; most likely it is not a question of a simple correlation between the amount of reading and text quality, but rather a question about what they look at and when they do it.

As regards proof reading, studies have found that participants read familiar texts more quickly (e.g., Levy \& Begin, 1984) and corrected them more accurately (e.g., Levy, Di Persio, \& Hollingshead, 1992), suggesting that reading one's own text for evaluation is indeed a different process from reading someone else's for understanding. In addition, Pilotti and colleagues (e.g., Pilotti, Maxwell, \& Chodorow, 2006) showed that auditory feedback improved the accuracy of error correcting due to the proofreading, and thus suggested that for optimal proofreading performance writers should read aloud, indicating that not only written but also spoken language functions can play an important role in advanced text production. The term reading has in writing research been used to cover more or less everything that involves the use of visual feedback from the emerging and finished texts. In practice, however, this involves patterns such as following the cursor or the inscription point of the pen, quick scans to individual words earlier in the text, backtracking from the inscription point, and rereading words, sentences, or other parts of the texts; these patterns 
can most likely have different functions in different contexts. It is important to examine how good and poor reading and writing skills may impact upon children's use of reading as an executive control device in writing. So far the empirical data on this topic are scarce both for the development of reading and writing and for reading and writing difficulties, but there are some interesting results. There seems to be little difference between age groups (Alamargot, Plane, Lambert \& Chesnet, 2010) and between groups with and without reading and writing difficulties (Wengelin, Johansson \& Johansson, 2014) in how much they read their emerging texts. However, writers with reading and writing difficulties do make significantly longer fixations than their peers when reading their own emerging texts, that is, they are slower readers than their peers even when it comes to reading their own texts. This pattern agrees with that of reading for understanding; Hutzler and Wimmer (2003) showed for example that German dyslexic readers made longer fixations than their peers when reading for understanding. Taken together these results indicate that reading difficulties could influence both reading for understanding and writers' reading for evaluation of their own emerging texts.

\section{Implications for Assessment and Intervention}

Significant implications for the assessment of writing problems and instructional intervention descend from our view of the reading-writing process interconnections. Our view of the developmental relationship between these two processes and of the nature of their relationship may influence important pedagogical decisions, such as whether to teach reading before writing or the reverse, or whether to adopt a holistic approach to the teaching of reading and writing or to teach critical reading and writing components separately. Already in 1985 , Kucer (1985) stated that

Recently a renewed interest in the nature of the relationship between reading and writing processes has emerged // Although the notion that reading and writing are related processes is not new, the fact that much of the current research is exploring commonalities, rather than differences, represents a departure from the past paradigms.

p. 317

However, 30 years later we still have limited knowledge about how the different processes interact. Understanding this is essential for evidence-based intervention, and it is clear that research needs to address the more fundamental 
questions about the relations between the cognitive, linguistic, and developmental processes of reading and writing. For example, Fitzgerald and Shanahan (2000) suggested that "If reading and writing really were identical and not just similar, then it may make sense to teach only reading or writing" (p. 43). We already know that this isn't the case, but the citation serves to illustrate that the way we model how reading and writing are connected will have implications for how we teach them.

On the plan of pedagogical intervention, since reading and writing require different abilities (e.g., different meaning-making processes), researchers and educators have developed separate curricula, instructional materials, and assessments for these two processes. This has led to instructional interventions addressed to improving reading skills (De Beni, Vocetti, Cornoldi, \& Gruppo, 2004; Palmer, Boon, \& Spencer, 2014) and writing skills (Berninger, Vaughan et al., 2002; Berry \& Mason, 2012), but the focus has rarely been on their integration (but see Boscolo et al., 2007, and Miller, McCardle, \& Long, 2014).

Moreover, despite the documented association between reading and writing problems in children (Katusic et al., 2009; Wakely et al., 2006) and the existence of research showing that some common cognitive and linguistic skills underpin the reading and writing processes (Carretti et al., 2013), relatively litthe effort is made in educational settings to support these underpinnings (e.g., memory skills, oral language skills, awareness of discourse rules) during reading and writing activities. Some studies have been carried out showing that proof reading can support the development of spelling (Martino, 1995; Torbe, 1977), and that the evaluation of the writer's own text is an important component in some approaches to strategy-based teaching (e.g., Graham \& Harris, 2005). In addition, Graham and Hebert (2010) carried out a meta-analysis on the effects of using writing to enhance reading comprehension and reading skills. They showed that students' comprehension of science, social studies, and language arts are improved if they write about what they read, that students' reading skills are improved by learning the skills and processes that go into crafting text. However, we still have limited understanding of the mechanisms underlying these results.

Although considering the relationship between reading and writing is crucial in assessment and intervention, it is important to focus on different levels or different components at different ages. For example, whereas the research suggests that supporting reading skills in primary grades might also influence written production (e.g., Abbott \& Berninger, 1993), earlier in the development of writing skills, oral language may play a more important role (Kim, Wagner, \& Foster, 2011). Therefore, as suggested by Kim and colleagues, disproportionate attention to word reading and decoding skills at the expense of attention 
to oral language skills may be a disservice to children's literacy development during the early phases of writing development.

Moreover, the lack of a significant relationship at a certain moment shouldn't lead to the assumption that either the reading or writing problem of the child are isolated areas of deficits, or that the deficit of the child in one system will not affect the development of his or her skills in the other system. Finally, even when problems are domain-specific, this does not mean that intervention on reading cannot affect writing or vice versa.

\section{References}

Abbott, R., \& Berninger V. (1993) Structural equation modeling of relationships among developmental skills and writing skills in primary and intermediate grade writers. Journal of Educational Psychology, 85(3):478-508.

Alamargot, D., Chesnet, D., Dansac, C., \& Ros, C. (2006). Eye and pen: A new device for studying reading during writing. Behavior Research Methods Instruments \& Computers, 38(2), 287-299.

Alamargot, D., Plane, S., Lambert, E., \& Chesnet, D. (2010). Using eye and pen movements to trace the development of writing expertise: Case studies of a 7 th, gth, and 12th grader, graduate student, and professional writer. Reading and Writing: An Interdisciplinary Journal, 23, 853-888.

Angelelli, P., Marinelli, C.V., \& Zoccolotti, P. (2010). Single or dual orthographic representations for reading and spelling? A study of Italian dyslexic-dysgraphic and normal children. Cognitive Neuropsychology, 27(4), 305-333.

Arfé, B., \& Boscolo, P. (2006). Causal coherence in deaf and hearing students' written narratives. Discourse Processes, 42(3), 271-300.

Arfé, B., Dockrell, J., \& Berninger, V. (2014). Writing development in children with hearing loss, dyslexia and oral language problems. Implications for assessment and instruction. NY: Oxford University Press.

Babayigit, S., \& Stainthorp, R. (2011). Modeling the relationships between cognitivelinguistic skills and literacy skills: New insights from a transparent orthography. Journal of Educational Psychology, 103(1), 169-189.

Berninger, V., \& Abbott, D. (2010). Listening comprehension, oral expression, reading comprehension and written expression: Related yet unique language systems in grades 1, 3, 5, and 7. Journal of Educational Psychology, 102, 635-651.

Berninger, V.W., Abbott, R., Abbott, S., Graham, S., \& Richards, T. (2002) Writing and reading: Connections between language by hand and language by eye. Journal of Learning Disabilities, $35,39-56$

Berninger, V.W., Vaughan, K.B., Abbott, R.D., Brooks, A., Begay, K., Coleman, K.B., ... Gra- 
ham, S. (2002). Teaching spelling and composition alone and together: Implications for the simple view of writing. Journal of Educational Psychology, 94, 291-304.

Berry, A.B., \& Mason, L.H. (2012). The effects of self-regulated strategy development on the writing of expository essays for adults with written expression eifficulties: Preparing for the GED. Remedial and Special Education, 33(2), 124-136.

Brandt, D. (2011). Literacy as involvement: The acts of writers, readers, and texts. Carbondale, IL: Southern Illinois University Press.

Boscolo, P., Arfé, B., \& Quarisa, M. (2007). Improving the quality of students' academic writing: An intervention study. Studies in Higher Education, 32(4), 419-438.

Cain, K., Oakhill, J., \& Bryant, P. (2004). Children's reading comprehension ability: Concurrent prediction by working memory, verbal ability, and component skills. Journal of Educational Psychology, 96(1), 31-42. doi: 10.1037/oo22-0663.96.1.31

Caramazza, A. (1988). Some aspects of language processing revealed through the analysis of acquired aphasia: The lexical system. Annual Review of Neuroscience, 11, 395421.

Carretti, B., Re, A.M., \& Arfé, B. (2013). Reading comprehension and expressive writing: A comparison between good and poor comprehenders. Journal of Learning Disabilities, $46(1), 87-96$.

Connelly, V. (2014). Integrating writing and oral language disorders. In B. Arfé, J. Dockrell, \& V.W. Berninger (Eds.), Writing development in children with hearing loss, dyslexia, or oral language problems. Implications for assessment and instruction (pp. 313324). NY: Oxford University Press.

Coltheart, M. (1978). Lexical access in simple reading tasks. In G. Underwood (Ed.), Strategies of information processing (pp. 151-216). London: Academic Press.

Coltheart, M. (2005). Modelling reading: The dual-route approach. In M.J. Snowling \& C. Hulme (Eds.), The science of reading: A handbook (pp. 6-23). Maiden: Blackwell Publishing.

Coltheart, M., Curtis, B., Atkins, P., Haller, M. (1993). Models of reading aloud: Dualroute and parallel-distributed-processing approaches. Psychological Review. 10o(4), $589-6 \circ 8$.

De Beni, R., Vocetti, C., Cornoldi, C., \& Gruppo M.T. (2004). Nuova Guida alla Comprensione. [New guide to comprehension] Volumes 3 and 4. Trento: Erickson.

Ehri, L.C. (2005). Learning to read words: Theory, findings, and issues. Scientific Studies of Reading, 9, 167-188.

Fitzgerald, G., \& Shanahan, T. (2000). Reading and writing relations and their development. Educational Psychologist, 35, 39-51.

Gough, P.B., \& Tunmer, W.E. (1986). Decoding, reading, and reading disability. Remedial and Special Education, 7, 6-10.

Graham, S., \& Harris, K. (2005). Writing better: Effective strategies for teaching students with learning difficulties. Baltimore, MD: Paul H. Brookes Publishing Company. 
Graham, S., \& Herbert, M.A. (2010). Writing to read: Evidence for how writing can improve reading. A Carnegie Corporation Time to Act Report. Washington, DC: Alliance for Excellent Education.

Hatcher, J., Snowling, M.J., \& Griffiths, Y.M. (2002). Cognitive assessment of dyslexic students in higher education. British Journal of Educational Psychology, 72, 119-133.

Hayes, J.R. (1996). A new framework for understanding cognition and affect in writing. In C.M. Levy \& S.E. Ransdell (Eds.), The Science of Writing: Theories, Methods, Individual Differences, and Aapplications (pp. 1-27). Mahwah, New Jersey: Lawrence Erlbaum Associates.

Hayes, J.R., Flower, L., Schriver, K.A., Stratman, J., \& Carey, L. (1987). Cognitive processes in revision. In S. Rosenberg (Ed.), Advances in applied psycholinguistics, Volume II: Reading, writing, and language processing (pp. 176-240). Cambridge, England: Cambridge University Press.

Hayes, J.R., \& Berninger, V.W. (2014). Cognitive processes in writing: A framework. In B. Arfé, J. Dockrell, \& V.W. Berninger. (Eds.), Writing development in children with hearing loss, dyslexia, or oral language problems. Implications for assessment and instruction (pp. 3-15). NY: Oxford University Press.

Hayes, J.R., \& Flower, L.S. (1980). Identifying the organization of writing processes. In L.W. Gregg \& E.R. Steinberg (Eds.), Cognitive processes in writing (pp.3-30). Mahwah, NJ: Lawrence Erlbaum Asssociates.

Hayes, J., Flower, L., Schriver, K., Stratman, J.F., \& Carey, L. (1987). Cognitive processes in revision. Advances in applied psycholinguistics: Volume 2, Reading, writing, and language learning (pp. 177-235). Cambridge, England: Cambridge University Press.

Hebert, M., Gillespie, A., \& Graham, S. (2013). Comparing effects of different writing activities on reading comprehension: A meta-analysis. Reading and Writing, 26, 111138.

Holmqvist, K., Holsanova, J., Johansson, V., \& Strömqvist, S. (2004). Perceiving and producing the frog story. In D. Ravid \& H.B.Z. Shyldkrot. (Eds.), Perspectives on language and language development. Essays in honor of Ruth A. Berman (pp. 2933o6). Dordrect: Kluwer Academic Press.

Hoover, W.A., \& Gough, P.B. (1990). The simple view of reading. Reading and Writing, 2(2), 127-16o.

Hutzler, F., \& Wimmer, H. (2003) Eye movements of dyslexic children when reading in a regular orthography. Brain \& Language 89, 235-242

Johansson, R., Johansson, V., Wengelin, Å., \& Holmqvist, K. (2008). Reading during writing: Four groups of writers. Working Papers 53 (pp. 43-59). Lund, Sweden: Lund University, Department of Linguistics.

Johansson, R., Wengelin, Å., Johansson, V., \& Holmqvist, K. (2010). Looking at the keyboard or the monitor: Relationship with text production processes. Reading and Writing: An Interdisciplinary Journal, 23(7), 835-851. 
Juel, C. (1988). Learning to read and write: A longitudinal study of 54 children from first through fourth grades. Journal of Educational Psychology, 8o(4), 437.

Juel, C. (1998). What kind of one-on-one tutoring helps a poor reader? In C. Hulme \& R.M. Joshi (Eds.), Reading and spelling: Development and disorders. (pp. 449-471). Mahwah, NJ: Lawrence Erlbaum Associates.

Katusic, S.K., Colligan, R.C., Weaver, A.L., \& Barbaresi, W.J. (2009). The forgotten learning disability: Epidemiology of written-language disorder in a population-based birth cohort (1976-1982), Rochester, Minnesota. Pediatrics, 123(5), 1306-1313.

Kaufer, D.S., Hayes, J.R., \& Flower, L.S. (1986). Composing written sentences. Research in the Teaching of English, 20(2), 121-140.

Kim, Y.S., Wagner, R.K., \& Foster, E. (2011). Relations among oral reading fluency, silent reading fluency, and reading comprehension: A latent variable study of first-grade readers. Scientific Studies of Reading, 15(4), 338-362.

Kintsch, W. (2004). The Construction-Integration model of text comprehension and its implications for instruction. In R. Ruddell \& N. Unrau (Eds.), Theoretical models and processes of reading (5th ed.). Newark, DE: International Reading Association.

Kintsch, W., \& van Dijk, T.A. (1978). Toward a model of text comprehension and production. Psychological Review, 85(5), 363.

Kucer, S.L. (1985). The making of meaning: Reading and writing as parallel processes. Written Communication, 2(3), 317-336.

Levy, B.A., \& Begin, J. (1984). Proofreading familiar text: Allocating resources to perceptual and conceptual processes. Memory \& Cognition, 12(6), 621-632.

Levy, B., Di Persio, R., \& Hollinghead, A. (1992). Fluent rereading: Repetition, automaticity, and discrepancy. Journal of Experimental Psychology: Learning, Memory, \& Cognition, 18, 957-971.

Martino, N. (1995). An examination of the relationship between practices and processes of proofreading and spelling developing literacy learners. Unpublished honors thesis, University of Wollongong, Australia.

McGee, L.M., \& Richgels, D.J. (1996). Literacy's beginnings: Supporting young readers and writers (2nd ed.). Needham, MA: Allyn \& Bacon.

Mehta, P.D., Foorman, B.R., Branum-Martin, L., \& Taylor, W.P. (2005). Literacy as a unidimensional multilevel construct: Validation, sources of influence, and implications in a longitudinal study in grades 1 to 4. Scientific Studies of Reading, 9(2), $85^{-116 .}$

Miller, B., McCardle, P., \& Long, R. (Eds.) (2014). Teaching reading \& writing: Improving instruction \& student achievement. Baltimore, MD: Paul H. Brookes Publishing Co.

Nauclér, K., \& Magnusson, E. (2002). How do preschool language problems affect language abilities in adolescence? In F. Windsor \& M.L. Kelly (Eds.), Investigations in clinical phonetics and lingustics (pp. 99-114). Mahwah, NJ: Erlbaum.

Nottbusch, G. (2010). Grammatical planning, execution, and control in written sentence production. Reading and Writing, 23(7), 777-801. 
Nunes, T., Bryant, P., \& Bindman, M. (1997). Morphological spelling strategies: Developmental stages and processes. Developmental Psychology, 33(4), 637-649.

Olinghouse, N.G. (2008). Student- and instruction-level predictors of narrative writing in third-grade students. Reading and Writing, 21(1-2), 3-26.

Ouellette, G., \& Sénéchal, M. (20o8). Pathways to literacy: A study of invented spelling and its role in learning to read. Child Development, 79, 899-913.

Palmer, J., Boon, R.T., \& Spencer, V.G. (2014). Effects of concept mapping instruction on the vocabulary acquisition skills of seventh-graders with mild disabilities: A replication study. Reading \& Writing Quarterly, 3o(2), 165-182.

Pilotti, M., Maxwell, K., \& Chodorow, M. (2006). Does the effect of familiarity on proofreading change with encoding task and time? The Journal of General Psychology, 133(3), 287-299.

Richards, T.L., Aylward, E.H., Field, K.M., Grimme, A.C., Raskind, W., Richards, A.L., ... Berninger, V.W. (2006). Converging evidence for triple word form theory in children with dyslexia. Developmental Neuropsychology, 30(1), 547-589.

Seidenberg, M.S., \& McClelland, J.L. (1989). A distributed, developmental model of word recognition and naming. Psychological Review, 96(4), 523-568.

Shahar-Yames, D., \& Share, D.L. (2008). Spelling as a self-teaching mechanism in orthographic learning. Journal of Research in Reading, 31, 22-39.

Shatil, E., Share, D.L., \& Levin, I. (2000). On the contribution of kindergarten writing to grade 1 literacy: A longitudinal study in Hebrew. Applied Psycholinguistics, 21(1), 1-21.

Sumner, E., Connelly, V., \& Barnett, A.L. (2014). The influence of spelling ability on vocabulary choices when writing for children with dyslexia. Journal of Experimental Psychology: Learning, Memory, and Cognition, 40(5), 1441-1447.

Swanson, H.L., \& Berninger, V.W. (1996). Individual differences in children's working memory and writing skill. Journal of Experimental Child Psychology, 63(2), 358-385.

Tainturier, M-J., \& Rapp, B. (2002). The spelling process. In B. Rapp (Ed.), The handbook of cognitive neuropsychology: What deficits reveal about the human mind (pp. 263290). Philadelphia, PA: Psychology Press.

Torbe, M. (1977). Teaching spelling. London: Ward Lock Educational.

Torrance, M., Johansson, R., Johansson, V., \& Wengelin, Å. (2016). Reading during the composition of multi-sentence texts: An eye-movement study. Psychological Research, 8o(5), 729-743.

Torrance, M., Rønneberg, V., Johansson, C., \& Uppstad, P.H. (2016). Adolescent weak decoders writing in a shallow orthography: process and product. Scientific Studies of Reading. 20(5) 375-388.

Torrance, M., \& Wengelin, Å. (2010). Writers' eye movements. In C. Bazerman, R. Krut, K. Lunsford, S. McLeod, S. Null, P. Rogers, \& A. Stansell. (Eds.), Traditions of writing research: Traditions, trends, and trajectories (pp. 394-405). New York: Routledge. 
Van Waes, L., Leijten, M., \& Quinlan, T. (2010). Reading during sentence composing and error correction: A multilevel analysis of the influences of task complexity. Reading and Writing: An Interdisciplinary Journal, 23(7), 803-834.

Vorstius, C., Radach, R., Mayer, M.B., \& Lonigan, C.J. (2013). Monitoring local comprehension monitoring in sentence reading. School Psychology Review, 42(2), 191-206.

Wang, H.-C., Marinus, E., Castles, A., \& Nickels, L. (2014). Tracking orthographic learning in children with different profiles of reading difficulty. Frontiers in Human Neuroscience, 8, 468. doi:10.3389/fnhum.2014.00468

Wakely, M., Hooper, S., de Kruif, R., \& Swartz, C. (2006). Subtypes of written expression in elementary school children: A linguistic-based model. Developmental Neuropsychology, 29(1), 125-159.

Wengelin, Å., Johansson, V., \& Johansson, R. (2014). Expressive writing in Swedish 15year-olds with reading and writing difficulties. In B. Arfé, J. Dockrell, \& V. Berninger (Eds.), Writing development in children with hearing loss, dyslexia or oral language problems (pp. 244-256). New York: Oxford University Press.

Wengelin, Å., Leijten, M., \& Van Waes, L. (2010). Studying reading during writing: New perspectives in research. Reading and Writing: An Interdisciplinary Journal, 23(7), 735-742.

Wengelin, Å., Torrance, M., Holmqvist, K., Simpson, S., Galbraith, D., Johansson, V., \& Johansson, R. (2009). Combined eyetracking and keystroke-logging methods for studying cognitive processes in text production. Behavior Research Methods, 41(2), 337-351. 